\title{
Chemical and Pharmacological Studies of Saponins with a Focus on American Ginseng
}

\author{
Chun-Su Yuan", Chong-Zhi Wang, Sheila M. Wicks, and Lian-Wen Qi \\ Tang Center for Herbal Medicine Research and Department of Anesthesia \& Critical Care, University of Chicago Pritzker School \\ of Medicine, Chicago, IL 60637, USA
}

\begin{abstract}
Asian ginseng (Panax ginseng) and American ginseng (Panax quinquefolius L.) are the two most recognized ginseng botanicals. It is believed that the ginseng saponins called ginsenosides are the major active constituents in both ginsengs. Although American ginseng is not as extensively studied as Asian ginseng, it is one of the best selling herbs in the US, and has garnered increasing attention from scientists in recent years. In this article, after a brief introduction of the distribution and cultivation of American ginseng, we discuss chemical analysis of saponins from these two ginsengs, i.e., their similarities and differences. Subsequently, we review pharmacological effects of the saponins, including the effects on the cardiovascular system, immune system, and central nervous system as well as the anti-diabetes and anti-cancer effects. These investigations were mainly derived from American ginseng studies. We also discuss evidence suggesting that chemical modifications of ginseng saponins would be a valuable approach to develop novel compounds in drug discovery.
\end{abstract}

Keywords: Asian ginseng, Panax ginseng, American ginseng, Panax quinquefolius L., Saponins, Ginsenoside, Pharmacology

\section{INTRODUCTION}

Ginseng root has been used for thousands of years in the traditional medical system in oriental countries. Asian ginseng (Panax ginseng) and American ginseng (Panax quinquefolius L.) are the two most recognized herbal medicines in the world. Throughout the past few decades, American ginseng has become increasingly popular in the West. Like Asian ginseng, American ginseng has been reported to have a wide range of pharmacological effects such as cardiovascular and central nervous system effects, anti-diabetes effects, anti-tumor activities, and immunomodulation [1-3].

It is generally accepted that the triterpene saponins called ginsenosides are the major active constituents in ginseng [3-4]. The therapeutic importance of ginseng has led to the development of a wide spectrum of ana- lytical methods for the determination of the total saponin content, group-specific analysis, and target compound determination. The pharmacokinetics and metabolism of different ginseng saponin compounds have been studied in both animals and humans [5].

Compared to the long history and widespread research of Asian ginseng, the study of American ginseng and its constituents is much less extensive. However, many investigations on American ginseng have been published in past decade. In this article, after a brief introduction of American ginseng, we discuss the chemical analysis of saponins from these two ginsengs, and review pharmacological activities of saponins, including updating research progress in saponins from American ginseng.

\footnotetext{
(c) This is an Open Access article distributed under the terms of the Creative Commons Attribution Non-Commercial License (http://creativecommons.org/licenses/by-nc/3.0/) which permits unrestricted non-commercial use, distribution, and reproduction in any medium, provided the original work is properly cited.
}

Received 16 Jul. 2010, Revised 23 Aug. 2010, Accepted 26 Aug. 2010

*Corresponding author

E-mail: cyuan@uchicago.edu

Tel: +1-773-702-1916, Fax: +1-773-834-0601 


\section{AMERICAN GINSENG AND ITS CULTIVATION}

American ginseng is distributed in the eastern temperate forest areas of North America, from southern Quebec, Minnesota, and Wisconsin in the north, to Oklahoma, the Ozark Plateau, and Georgia in the south. American ginseng was first introduced in the "New Compilation of Materia Medica" in 1757 [6]. In the West, American ginseng was recorded in Quebec, Canada in the early 18 th century and has since generated a lot of interest [7].

As a perennial herb, most wild populations of American ginseng thrive in the upland, north- and east-facing woods where shade and loam soils are typical. Methods of cultivation, botanical characteristics, and authentication of this plant have been described in detail [8]. There are three kinds of American ginseng available on the market: cultivated, simulated wild, and wild. Like Asian ginseng, those growing wild are the best and most expensive. In addition, American ginseng is currently being cultivated in some Asian countries, like China.

\section{STRUCTURAL DIVERSITY OF GINSENOSIDES}

Ginsenosides belong to a family of steroids with a four trans-ring rigid steroid skeleton. Most ginsenosides share a unique triterpenoid saponin structure of the dam- marane type [9]. More than 100 ginsenosides have been isolated from roots, leaves, stems, flower buds, and berries of Asian ginseng and American ginseng and these ginsenosides exhibit considerable structural variation [4]. Ginsenosides differ from one another by the type of sugar moieties, sugar number, and site of sugar attachment at positions C-3, C-6, or C-20. The structural isomerism and stereoisomerism, the number and site of attachment of hydroxyl groups, and available modified side chain at C-20 also increase their diversity.

Ginsenosides from ginseng are divided into several groups (Fig. 1). Protopanaxadiol (PPD) and protopanaxatriol (PPT) groups are the main constituents, while ocotillol and oleanane groups are minor ones [10,11]. The PPD group has sugar moieties attached to the $\beta-\mathrm{OH}$ at $\mathrm{C}-3$ and/or C-20, and the PPT group has sugar moieties attached to the $\alpha-\mathrm{OH}$ at $\mathrm{C}-6$ and/or $\beta-\mathrm{OH}$ at $\mathrm{C}-20$ $[4,5,12]$. The ocotillol group has a five-membered epoxy ring at $\mathrm{C}-20$, and the oleanane group has a modified C-20 side chain [13].

Chemically, several differences exist between Asian ginseng and American ginseng. An important parameter used for this differentiation is the presence of ginsenoside $\mathrm{Rf}$ in Asian ginseng but pseudoginsenoside F11 in American ginseng [14]. HPLC-ELSD or HPLC-MS can be used to detect both F11 and Rf. In addition, ratios of $\mathrm{Rg} 1 / \mathrm{Rb} 1$ and $\mathrm{Rb} 2 / \mathrm{Rb} 1$ are useful. Both ratios less than
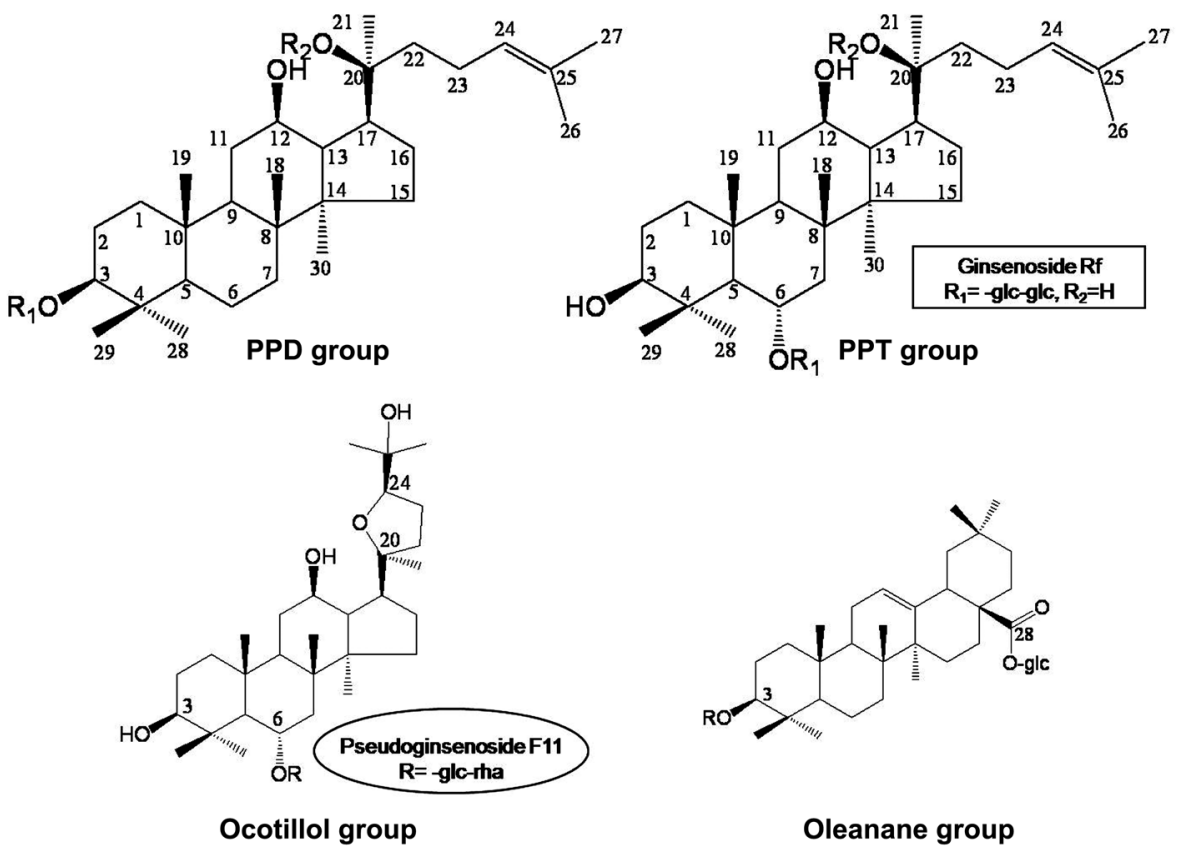

Fig. 1. Core chemical structures of four types of triterpenoid saponins from ginseng, i.e., protopanaxadiol (PPD) group, protopanaxatriol (PPT) group, ocotillol group, and oleanane group. Ginsenoside Rf (in square) is uniquely present in Asian ginseng, and pseudoginsenoside F11 (in circle) is uniquely present in American ginseng. 
0.4 is indicative of American ginseng, while a high value of ratios is characteristic of Asian ginseng [15]. One exception is wild American ginseng, which may have a high $\mathrm{Rg} 1 / \mathrm{Rb} 1$ ratio [16].

Like Asian ginseng, a recent study on American ginseng shows that ginsenoside content also varies among different parts of the plant. The leaf contains the highest ginsenosides $(16.5 \%)$, followed by root-hair $(6.9 \%)$, rhizome $(5.1 \%)$, root $(4.9 \%)$ and stem $(2.0 \%)$ [10]. The content of ginsenosides increases with the age of the plant parts, except the leaf [17]. In general, ginsenoside $\mathrm{Rb}_{1}, \mathrm{Re}, \mathrm{Rd}, \mathrm{Rc}, \mathrm{Rg} 1$, and $\mathrm{Rb} 3$ are the six major saponins in American ginseng, accounting for more than $70 \%[10,11,18]$. Variability in individual ginsenosides and total ginsenoside amount has been observed in different commercial products of American ginseng, which is in part associated with natural variations such as climate, geographical location, and cultivation length and conditions $[18,19]$. This ginsenoside variability in different ginseng products may also be responsible for different or even opposing reported pharmacological activities [20]. Thus, the importance of standardization of ginseng products should be primarily emphasized.

To mimic Korean (or Asian) red ginseng, American red ginseng can be prepared experimentally using steaming or heating treatment (e.g., at $120^{\circ} \mathrm{C}$ for 4 hours) [21]. The chemical composition of the steamed American ginseng is quite different from than the untreated ginseng. The steaming process causes obvious chemical degradation and conversion of original saponins to some newly occurring compounds [21]. The polar ginsenosides including $\mathrm{Rg}_{1}, \mathrm{Re}, \mathrm{Rb}_{1}, \mathrm{Rc}, \mathrm{Rb}_{2}, \mathrm{Rb}_{3}$, and $\mathrm{Rd}$ decrease remarkably, while less polar ginsenosides, including Rg2, Rg3, Rg5, Rh2, Rk1, and Rs4 increase [22,23]. Due to the change in ginsenoside profile, the steaming treatment may enhance American ginseng's effects, such as increasing its anti-cancer activities [21,24].

\section{MULTIPLE PHARMACOLOGICAL EFFECTS OF GINSENOSIDES}

\section{Effects on the cardiovascular system}

Cardiovascular disease continues to be the leading cause of death in the U.S. Recent studies have incriminated reactive oxygen species in the pathogenesis of both acute and chronic heart disease. Many botanicals possess antioxidant properties, and these herbal antioxidants may protect against cardiovascular diseases by contributing to the total antioxidant defense system of the human body. Total ginseng saponins administered to rats having the myocardium damaged by injury to the left anterior descending coronary artery were shown to protect the myocardium with an anti-ischemic action, probably related to a decrease in free fatty acid levels and an elevation of lactate dehydrogenase activity. The saponins may also produce a $\mathrm{Ca}^{2+}$ channel blocking effect [25]. In another report, American ginseng root saponins displayed the ability to significantly decrease platelet aggregation rates and to increase superoxide dismutase activity in hyperlipidaemic rats [26].

The acute antioxidant and protective effect of American ginseng berry extract has been demonstrated in cultured cardiomyocytes and pretreatment with the extract up-regulating peroxide detoxifying mechanisms, which could affect intracellular oxidant dynamics [27]. We observed that the extract has a stronger antioxidant activity compared to that of the Asian ginseng root [27,28]. A subsequent study showed that ginsenoside Re, the major constituent in the extract, functions as an antioxidant by protecting cardiomyocytes from injury induced by both exogenous and endogenous oxidants, the protective effects of which may be mostly attributed to scavenging $\mathrm{H}_{2} \mathrm{O}_{2}$ and hydroxyl radicals [29]. In an acute myocardial infarction rat model, the effect of American ginseng saponins can protect myocardium from ischemic injury in rats after the infarction by way of promoting angiogenesis in the affected area of myocardium and up-regulating expressions of vascular endothelial growth factor and basic fibroblast growth factor in myocardial cells [30]. The antioxidant saponin components and their activities have been reviewed and relationships between the observed effects and the chemical structures have been explored [30-32].

\section{Anti-diabetes effects}

Type 2 diabetes, a serious chronic metabolic disorder, represents a syndrome with disordered metabolism of carbohydrates and lipids. Early research showed that both Asian ginseng and American ginseng roots possess significant hypoglycemic abilities in diabetic mice models [33-35]. Using an $o b / o b$ mouse model, our data demonstrated that American ginseng leaf and berry extracts decreased fasting blood glucose, improved glucose disposal, and reduced body weight following a 12-day treatment [36,37]. Ginsenoside Re was identified as an active anti-diabetic constituent in American ginseng berry extract $[34,38]$. Ginsenoside $\mathrm{Rb}_{1}$, the major constituent in American ginseng root, was found to possess antidiabetic and insulin-sensitizing activities [39]. The $\mathrm{Rb}_{1}$ stimulated glucose transport in insulin-sensitive cells 
by promoting translocations of GLUT1 and GLUT4 by partially activating the insulin-signaling pathway [40]. In another study, $\mathrm{Rb}_{1}$ was observed to promote glucosestimulated insulin secretion through protein kinase A, which augmented insulin receptor substrate 2 expression to enhance insulin/IGF-1 signaling [41].

It has been reported that oxidative stress is linked to diabetes $[42,43]$. As a botanical antioxidant, American ginseng may also protect against diabetes by contributing to the total antioxidant defense system of the body [37]. However, since indirect evidence suggests that the antidiabetic effects of American ginseng may not be linked to antioxidant activity [44], more research is needed.

\section{Effects on the central nervous system}

Ginseng has both stimulatory and inhibitory effects on the central nervous system, and may modulate neurotransmission. Ginsenosides are responsible for ginseng's effects on the central nervous system (CNS) and the peripheral nervous system [45]. The effect of ginsenoside $\mathrm{Rg}_{1}$ or $\mathrm{Rb}_{1}$ was also examined and both enhance CNS activities, but the effect of the latter is weaker [46], sometimes even having an inhibitory effect on the CNS. Since American ginseng has a lower ratio of $\mathrm{Rg}_{1} / \mathrm{Rb}_{1}$ content, American ginseng is "cool" or calming to the CNS.

The protective effects of Ginsenosides $\mathrm{Rb}_{1}, \mathrm{Rg}_{1}, \mathrm{Rg}_{3}$, and $\mathrm{Rh}_{2}$ on neurodegeneration are well studied $[45,47] . \mathrm{Rb}_{1}$ has been shown to partially prevent the memory deficits caused by the cholinergic agent scopolamine in a rat model [48]. Ginsenosides regulate various types of ion channels, such as voltage-dependent and ligand-gated ion channels, in neuronal and heterologously expressed cells. Ginsenosides inhibit voltage-dependent $\mathrm{Ca}^{2+}, \mathrm{K}^{+}$, and $\mathrm{Na}^{+}$channel activities in a stereospecific manner. They also inhibit ligand-gated ion channels such as $\mathrm{N}$ methyl-d-aspartate, some subtypes of nicotinic acetylcholine, and 5-hydroxytryptamine type 3 receptors [49].

In vivo studies have demonstrated that ginsenosides improve spatial learning and increase hippocampal synaptophysin levels in mice [50], reduce infarct and neuronal deficit on transient cerebral [51], and effectively attenuate Tau protein hyperphosphorylation of hippocampal neurons [52]. In addition, ginsenosides promote neurotransmitter release by increasing the phosphorylation of synapsins [53]. Competition and site-directed mutagenesis experiments revealed that ginsenosides interact with ligand-binding sites or channel pore sites and inhibit open states of ion channels [46]. Recent reports show that long-term ginsenoside consumption could prevent memory loss and impairment by decreasing oxidative stress and up-regulating the plasticity-related proteins in the hippocampus $[54,55]$. These observations suggest that ginseng and some ginsenosides may rescue or protect neurons from insult, and may be a promising candidate to improve the cognitive deficit of Alzheimer's disease.

\section{Anti-cancer effects}

American ginseng can potentially be used for cancer treatment and chemotherapy induced side-effect management. In in vitro studies, American ginseng was found to inhibit the growth of breast cancer cells $[56,57]$. After steaming treatment of American ginseng, its antiproliferative effects on cancer cells were improved significantly, possibly due to the altered ginsenoside profile $[21,24]$. Anti-proliferative effects of representative constituents were also evaluated, showing that ginsenoside $\mathrm{Rg}_{3}$ has a positive effect. Steamed American ginseng inhibited the colorectal cancer growth both in vitro and in vivo, which might be achieved through cell cycle arrest and induced apoptosis in the cells [58].

The cellular and molecular targets of ginsenosides against cancer have also been studied. It appears that several molecular mechanisms exist and collectively converge on various signaling pathways. These pathways include regulation of cell cycle, induction of apoptosis, inhibition of angiogenesis, prohibition of invasion, and reduction of inflammatory response [59,60]. A series of cell cycle proteins, apoptosis-related proteins, growth factors, protein kinases, and transcription factors are affected by ginsenosides [59-61]. For example, Rh2 and $\operatorname{Rg} 3$ inhibit cancer cell proliferation by inducing gene and protein expression of the cell cycle regulatory protein $\mathrm{p} 21$, thus arresting tumor cell cycle progression by inducing cancer cell apoptosis through activation of caspase-3 protease via a bcl-2-insensitive pathway and by sensitizing multidrug-resistant tumor cells to chemotherapy [62-64]. To characterize further downstream genes targeted by ginseng saponins such as Rg3 in a human cancer cell line, the gene expression profiling was assayed, showing that the most affected pathway was the Ephrin receptor pathway [65].

The most commonly used cancer chemotherapies are limited by severe side effects and dose-limiting toxicity. The drug-related adverse events not only worsen patients' quality of life, but can also lead to refusal to continue the potentially curative chemotherapy. American ginseng and ginsenoside Re attenuated cisplatin-induced nausea and vomiting in a rat model without affecting its anti-cancer properties in human cancer cells $[66,67]$. 


\section{Effects on the immune system}

Ginseng's anticancer effects have been considered to be linked to its activity within the immune system [68]. Ginsenosides enhance the formation of antibodies and immune functions in cancer patients and in microbeinfected experimental laboratory animals, possibly by elevation of the cAMP levels. Ginsenosides $\mathrm{Rb}_{2}$, Rc, and $\mathrm{Rg}_{1}$ have been shown to stimulate DNA synthesis in bone marrow cells possibly by the involvement of cyclic nucleotides [69]. An in vivo study showed that the total saponin of American ginseng partially restored the activity of cyclophosphamide-depressed bone marrow stem cell proliferation and splenocyte proliferation in mice and enhanced production of interleukin (IL)-3 and IL-6-like substances from the splenocytes. The total saponin may also oppose the depressant effects of cyclophosphamide and other chemotherapeutic agents on the bone marrow stem cell proliferation by control of hemopoietic growth factor production in the splenocytes [70].

A ginseng polysaccharide-rich extract showed the enhancement of lymphocyte transformation, induction of IFN- $\gamma$ and IL-1 production, and stimulation of spleencell production of an IL-3-like cytokine activity [71]. The effect of the polysaccharide-rich extract on systemic and gut-associated immune function was evaluated in comparison to American ginseng saponins. The extract modified systemic immune responses and appeared to affect gut-associated immunity in a manner distinct from that of the saponins [72].

\section{CONCLUSION}

Previous chemical analysis data demonstrated that ginseng saponins possess diversity in their structures. Ginsenosides can also be transformed to other compounds by steaming treatment. These saponins have low bioavailability, and gut ginsenoside transformations would further complicate the prediction of ginseng's clinical effectiveness [73-75].

There are many published clinical studies using ginseng on cardiovascular disease, diabetes, and fatigue. Since most these trials used ginseng root or the root extract but not the identified saponins, discussion of clinical effects of ginseng or its extracts is beyond the scope of this article. Although some pharmacological activities are known, there are probably many more unknown aspects regarding ginseng saponin's mechanisms of action, and further investigations are required. Chemical modifications are a suitable way to establish a library of new compounds from ginseng saponins, and this ap- proach would provide an opportunity to develop novel compounds in drug discovery.

\section{ACKNOWLEDGEMENTS}

This work was supported in part by the NIH grants P01 AT004418 and K01 AT005362.

\section{REFERENCES}

1. Court WE. Ginseng: the history of an insignificant plant. Pharm Hist (Lond) 2000;30:38-44.

2. Ang-Lee MK, Moss J, Yuan CS. Herbal medicines and perioperative care. JAMA 2001;286:208-216.

3. Attele AS, Wu JA, Yuan CS. Ginseng pharmacology: multiple constituents and multiple actions. Biochem Pharmacol 1999;58:1685-1693.

4. Jia L, Zhao Y. Current evaluation of the millennium phytomedicine--ginseng (I): etymology, pharmacognosy, phytochemistry, market and regulations. Curr Med Chem 2009; 16:2475-2484.

5. Christensen LP. Ginsenosides chemistry, biosynthesis, analysis, and potential health effects. Adv Food Nutr Res 2009;55:1-99.

6. Editor Board of Zhong Hua Ben Cao. The Chinese herbal (Zhong Hua Ben Cao). Shanghai: Shanghai Science and Technology Press, 1999.

7. Marie-Victorin F, Rouleau E. Flore laurentienne. 2nd ed. Montreal: Les Presses de l'Université de Montréal, 1964.

8. Ngan F, Shaw P, But P, Wang J. Molecular authentication of Panax species. Phytochemistry 1999;50:787-791.

9. Fuzzati N. Analysis methods of ginsenosides. J Chromatogr B Analyt Technol Biomed Life Sci 2004;812:119133.

10. Qu CL, Bai YP, Jin XQ, Wang YT, Zhang K, You JY, Zhang HQ. Study on ginsenosides in different parts and ages of Panax quinquefolius L. Food Chem 2009;115:340-346.

11. Wang A, Wang CZ, Wu JA, Osinski J, Yuan CS. Determination of major ginsenosides in Panax quinquefolius (American ginseng) using high-performance liquid chromatography. Phytochem Anal 2005;16:272-277.

12. Wang CZ, Yuan CS. Potential role of ginseng in the treatment of colorectal cancer. Am J Chin Med 2008;36:10191028.

13. Yoshikawa M, Murakami T, Yashiro K, Yamahara J, Matsuda H, Saijoh R, Tanaka O. Bioactive saponins and glycosides. XI. Structures of new dammarane-type triterpene oligoglycosides, quinquenosides I, II, III, IV, and V, from American ginseng, the roots of Panax quinquefolium L. Chem Pharm Bull (Tokyo) 1998;46:647-654. 
14. Shin YW, Bae EA, Kim DH. Inhibitory effect of ginsenoside $\mathrm{Rg} 5$ and its metabolite ginsenoside $\mathrm{Rh} 3$ in an oxazolone-induced mouse chronic dermatitis model. Arch Pharm Res 2006;29:685-690.

15. Nakamura S, Sugimoto S, Matsuda H, Yoshikawa M. Medicinal flowers. XVII. New dammarane-type triterpene glycosides from flower buds of American ginseng, Panax quinquefolium L. Chem Pharm Bull (Tokyo) 2007;55:13421348.

16. Schlag EM, McIntosh MS. Ginsenoside content and variation among and within American ginseng (Panax quinquefolius L.) populations. Phytochemistry 2006;67:15101519.

17. Zhang K, Wang X, Ding L, Li J, Qu CL, Chen LG, Jin HY, Zhang HQ. Determination of seven major ginsenosides in different parts of Panax quinquefolius L. (American ginseng) with different ages. Chem Res Chin Univ 2008;24:707-711.

18. Lim W, Mudge KW, Vermeylen F. Effects of population, age, and cultivation methods on ginsenoside content of wild American ginseng (Panax quinquefolium). J Agric Food Chem 2005;53:8498-8505.

19. Lin WN, Lu HY, Lee MS, Yang SY, Chen HJ, Chang YS, Chang WT. Evaluation of the cultivation age of dried ginseng radix and its commercial products by using (1)HNMR fingerprint analysis. Am J Chin Med 2010;38:205218.

20. Sengupta S, Toh SA, Sellers LA, Skepper JN, Koolwijk P, Leung HW, Yeung HW, Wong RN, Sasisekharan R, Fan TP. Modulating angiogenesis: the yin and the yang in ginseng. Circulation 2004;110:1219-1225.

21. Wang CZ, Aung HH, Ni M, Wu JA, Tong R, Wicks S, He TC, Yuan CS. Red American ginseng: ginsenoside constituents and antiproliferative activities of heat-processed Panax quinquefolius roots. Planta Med 2007;73:669-674.

22. Lau AJ, Seo BH, Woo SO, Koh HL. High-performance liquid chromatographic method with quantitative comparisons of whole chromatograms of raw and steamed Panax notoginseng. J Chromatogr A 2004;1057:141-149.

23. Kwon SW, Han SB, Park IH, Kim JM, Park MK, Park JH. Liquid chromatographic determination of less polar ginsenosides in processed ginseng. J Chromatogr A 2001;921:335-339.

24. Wang CZ, Zhang B, Song WX, Wang A, Ni M, Luo X, Aung HH, Xie JT, Tong R, He TC, et al. Steamed American ginseng berry: ginsenoside analyses and anticancer activities. J Agric Food Chem 2006;54:9936-9942.

25. Jin Y, Lu Z. Effect of PQS on FFA and LDH in rat myocardium damaged by injuring the left anterior descending coronary artery. Baiqiuen Yike Daxue Xuebao 1992;18:121-
122.

26. Li G, Yang S, Lui F. Effect of P. quinquefolius saponin on the platelet aggregation rate and superoxide dismutase activity in the hyperlipidaemic rats. Baiqiuen Yike Daxue Xuebao 1996;22:3.

27. Shao ZH, Xie JT, Vanden Hoek TL, Mehendale S, Aung H, Li CQ, Qin Y, Schumacker PT, Becker LB, Yuan CS. Antioxidant effects of American ginseng berry extract in cardiomyocytes exposed to acute oxidant stress. Biochim Biophys Acta 2004;1670:165-171.

28. Mehendale SR, Wang CZ, Shao ZH, Li CQ, Xie JT, Aung HH, Yuan CS. Chronic pretreatment with American ginseng berry and its polyphenolic constituents attenuate oxidant stress in cardiomyocytes. Eur J Pharmacol 2006;553:209-214.

29. Xie JT, Shao ZH, Vanden Hoek TL, Chang WT, Li J, Mehendale S, Wang CZ, Hsu CW, Becker LB, Yin JJ, et al. Antioxidant effects of ginsenoside Re in cardiomyocytes. Eur J Pharmacol 2006;532:201-207.

30. Wang CL, Shi DZ, Yin HJ. Effect of Panax quinquefolius saponin on angiogenesis and expressions of VEGF and bFGF in myocardium of rats with acute myocardial infarction. Zhongguo Zhong Xi Yi Jie He Za Zhi 2007;27:331-334.

31. Prior RL, Cao G, Prior RL, Cao G. Analysis of botanicals and dietary supplements for antioxidant capacity: a review. J AOAC Int 2000;83:950-956.

32. Wang CZ, Mehendale SR, Yuan CS. Commonly used antioxidant botanicals: active constituents and their potential role in cardiovascular illness. Am J Chin Med 2007;35:543-558.

33. Ng TB, Yeung HW. Hypoglycemic constituents of Panax ginseng. Gen Pharmacol 1985;16:549-552.

34. Attele AS, Zhou YP, Xie JT, Wu JA, Zhang L, Dey L, Pugh W, Rue PA, Polonsky KS, Yuan CS. Antidiabetic effects of Panax ginseng berry extract and the identification of an effective component. Diabetes 2002;51:1851-1858.

35. Dey L, Xie JT, Wang A, Wu J, Maleckar SA, Yuan CS. Anti-hyperglycemic effects of ginseng: comparison between root and berry. Phytomedicine 2003;10:600-605.

36. Xie JT, Wu JA, Mehendale S, Aung HH, Yuan CS. Antihyperglycemic effect of the polysaccharides fraction from American ginseng berry extract in ob/ob mice. Phytomedicine 2004;11:182-187.

37. Xie JT, Mchendale S, Yuan CS. Ginseng and diabetes. Am J Chin Med 2005;33:397-404.

38. Xie JT, Mehendale SR, Li X, Quigg R, Wang X, Wang CZ, Wu JA, Aung HH, A Rue P, Bell GI, et al. Anti-diabetic effect of ginsenoside Re in ob/ob mice. Biochim Biophys Acta 2005;1740:319-325. 
39. Shang W, Yang Y, Jiang B, Jin H, Zhou L, Liu S, Chen M. Ginsenoside Rb1 promotes adipogenesis in 3T3-L1 cells by enhancing PPARgamma2 and C/EBPalpha gene expression. Life Sci 2007;80:618-625.

40. Shang W, Yang Y, Zhou L, Jiang B, Jin H, Chen M. Ginsenoside Rb1 stimulates glucose uptake through insulinlike signaling pathway in 3T3-L1 adipocytes. J Endocrinol 2008;198:561-569.

41. Park S, Ahn IS, Kwon DY, Ko BS, Jun WK. Ginsenosides $\mathrm{Rb} 1$ and Rg1 suppress triglyceride accumulation in 3T3$\mathrm{L} 1$ adipocytes and enhance beta-cell insulin secretion and viability in Min6 cells via PKA-dependent pathways. Biosci Biotechnol Biochem 2008;72:2815-2823.

42. Stohs SJ. The role of free radicals in toxicity and disease. J Basic Clin Physiol Pharmacol 1995;6:205-228.

43. Cetin A, Kaynar L, Kocyigit I, Hacioglu SK, Saraymen R, Ozturk A, Sari I, Sagdic O. Role of grape seed extract on methotrexate induced oxidative stress in rat liver. Am J Chin Med 2008;36:861-872.

44. Xie JT, Wang CZ, Li XL, Ni M, Fishbein A, Yuan CS. Anti-diabetic effect of American ginseng may not be linked to antioxidant activity: comparison between American ginseng and Scutellaria baicalensis using an ob/ob mice model. Fitoterapia 2009;80:306-311.

45. Nah SY, Kim DH, Rhim H. Ginsenosides: are any of them candidates for drugs acting on the central nervous system? CNS Drug Rev 2007;13:381-404.

46. Chang Y, Huang WJ, Tien LT, Wang SJ. Ginsenosides $\mathrm{Rg} 1$ and $\mathrm{Rb} 1$ enhance glutamate release through activation of protein kinase A in rat cerebrocortical nerve terminals (synaptosomes). Eur J Pharmacol 2008;578:28-36.

47. Tian J, Fu F, Geng M, Jiang Y, Yang J, Jiang W, Wang C, Liu K. Neuroprotective effect of 20(S)-ginsenoside Rg3 on cerebral ischemia in rats. Neurosci Lett 2005;374:9297.

48. Benishin CG, Lee R, Wang LC, Liu HJ. Effects of ginsenoside Rb1 on central cholinergic metabolism. Pharmacology 1991;42:223-239.

49. Lee JH, Jeong SM, Kim JH, Lee BH, Yoon IS, Lee JH, Choi SH, Lee SM, Park YS, Lee JH, et al. Effects of ginsenosides and their metabolites on voltage-dependent $\mathrm{Ca}(2+)$ channel subtypes. Mol Cells 2006;21:52-62.

50. Mook-Jung I, Hong HS, Boo JH, Lee KH, Yun SH, Cheong MY, Joo I, Huh K, Jung MW. Ginsenoside Rb1 and Rg1 improve spatial learning and increase hippocampal synaptophysin level in mice. J Neurosci Res 2001;63:509-515.

51. Yuan QL, Yang CX, Xu P, Gao XQ, Deng L, Chen P, Sun ZL, Chen QY. Neuroprotective effects of ginsenoside Rb1 on transient cerebral ischemia in rats. Brain Res 2007;1167:112.
52. Chen X, Huang T, Zhang J, Song J, Chen L, Zhu Y. Involvement of calpain and p25 of CDK5 pathway in ginsenoside Rb1's attenuation of beta-amyloid peptide2535 -induced tau hyperphosphorylation in cortical neurons. Brain Res 2008;1200:99-106.

53. Xue JF, Liu ZJ, Hu JF, Chen H, Zhang JT, Chen NH. Ginsenoside Rb1 promotes neurotransmitter release by modulating phosphorylation of synapsins through a cAMP-dependent protein kinase pathway. Brain Res 2006;1106:9198.

54. Zhao H, Li Q, Pei X, Zhang Z, Yang R, Wang J, Li Y. Long-term ginsenoside administration prevents memory impairment in aged C57BL/6J mice by up-regulating the synaptic plasticity-related proteins in hippocampus. Behav Brain Res 2009;201:311-317.

55. Zhao H, Li Q, Zhang Z, Pei X, Wang J, Li Y. Long-term ginsenoside consumption prevents memory loss in aged SAMP8 mice by decreasing oxidative stress and upregulating the plasticity-related proteins in hippocampus. Brain Res 2009;1256:111-122.

56. Corbit R, Ebbs S, King ML, Murphy LL. The influence of lead and arsenite on the inhibition of human breast cancer MCF-7 cell proliferation by American ginseng root (Panax quinquefolius L.). Life Sci 2006;78:1336-1340.

57. Duda RB, Zhong Y, Navas V, Li MZ, Toy BR, Alavarez JG. American ginseng and breast cancer therapeutic agents synergistically inhibit MCF-7 breast cancer cell growth. J Surg Oncol 1999;72:230-239.

58. Xie JT, Wang CZ, Zhang B, Mehendale SR, Li XL, Sun S, Han AH, Du W, He TC, Yuan CS. In vitro and in vivo anticancer effects of American ginseng berry: exploring representative compounds. Biol Pharm Bull 2009;32:15521558.

59. Yue PY, Wong DY, Wu PK, Leung PY, Mak NK, Yeung HW, Liu L, Cai Z, Jiang ZH, Fan TP, et al. The angiosuppressive effects of 20(R)-ginsenoside Rg3. Biochem Pharmacol 2006;72:437-445.

60. Kim SY, Kim DH, Han SJ, Hyun JW, Kim HS. Repression of matrix metalloproteinase gene expression by ginsenoside Rh2 in human astroglioma cells. Biochem Pharmacol 2007;74:1642-1651.

61. Kim SM, Lee SY, Cho JS, Son SM, Choi SS, Yun YP, Yoo HS, Yoon do Y, Oh KW, Han SB, et al. Combination of ginsenoside Rg3 with docetaxel enhances the susceptibility of prostate cancer cells via inhibition of NF-kappaB. Eur J Pharmacol 2010;631:1-9.

62. Duda RB, Kang SS, Archer SY, Meng S, Hodin RA. American ginseng transcriptionally activates p21 mRNA in breast cancer cell lines. J Korean Med Sci 2001;16 Suppl:S54-S60. 
63. Park JA, Lee KY, Oh YJ, Kim KW, Lee SK. Activation of caspase-3 protease via a Bcl-2-insensitive pathway during the process of ginsenoside Rh2-induced apoptosis. Cancer Lett 1997;121:73-81.

64. Jia WW, Bu X, Philips D, Yan H, Liu G, Chen X, Bush JA, Li G. Rh2, a compound extracted from ginseng, hypersensitizes multidrug-resistant tumor cells to chemotherapy. Can J Physiol Pharmacol 2004;82:431-437.

65. Luo X, Wang CZ, Chen J, Song WX, Luo J, Tang N, He BC, Kang Q, Wang Y, Du W, et al. Characterization of gene expression regulated by American ginseng and ginsenoside $\mathrm{Rg} 3$ in human colorectal cancer cells. Int $\mathrm{J}$ Oncol 2008;32:975-983.

66. Aung HH, Mehendale SR, Wang CZ, Xie JT, McEntee E, Yuan CS. Cisplatin's tumoricidal effect on human breast carcinoma MCF-7 cells was not attenuated by American ginseng. Cancer Chemother Pharmacol 2007;59:369-374.

67. Mehendale S, Aung H, Wang A, Yin JJ, Wang CZ, Xie JT, Yuan CS. American ginseng berry extract and ginsenoside Re attenuate cisplatin-induced kaolin intake in rats. Cancer Chemother Pharmacol 2005;56:63-69.

68. Sonnenborn U. Recent investigations of the immunological, pharmacological and endocrinological activities of an old medicinal plant. Deutsch Apoth Zeit 1987;127:433441.

69. Court W E. Ginseng: the genus panax. Amsterdam: Harwood Academic Press, 2000.
70. Zhang D, Wang S, Chang Y, Han H. Effects of Panax quinquefolia saponins on hematopoietic growth factor in cyclophosphamide depressed mice. Baiqiuen Yike Daxue Xuebao 1992;18:412-414.

71. Zhuang M, Wu Y, Li M, Shu Y. Effects of some medicinal polysaccharides on immune deficiency in animal models induced by cobra anticomplementary factor. J Nat Toxins 1996;5:161-164.

72. Biondo PD, Goruk S, Ruth MR, O'Connell E, Field CJ. Effect of CVT-E002 (COLD-fX) versus a ginsenoside extract on systemic and gut-associated immune function. Int Immunopharmacol 2008;8:1134-1142.

73. Cui JF, Bjorkhem I, Eneroth P. Gas chromatographic-mass spectrometric determination of 20(S)-protopanaxadiol and 20(S)-protopanaxatriol for study on human urinary excretion of ginsenosides after ingestion of ginseng preparations. J Chromatogr B Biomed Sci Appl 1997;689:349355.

74. Tawab MA, Bahr U, Karas M, Wurglics M, Schubert-Zsilavecz M. Degradation of ginsenosides in humans after oral administration. Drug Metab Dispos 2003;31:10651071.

75. Hasegawa H. Proof of the mysterious efficacy of ginseng: basic and clinical trials: metabolic activation of ginsenoside: deglycosylation by intestinal bacteria and esterification with fatty acid. J Pharmacol Sci 2004;95:153-157. 